Sign Systems Studies 36.2, 2008

\title{
Humanities: State and prospects
}

\author{
Winfried Nöth, ${ }^{1}$ Eero Tarasti, ${ }^{2}$ Marek Tamm ${ }^{3}$
}

The developments in the humanities over the recent years could be characterised by the following three tendencies: florescence of methodological "turns", increasing importance of interdisciplinarity, and extensive travelling of concepts. Looking at the list of titles of the books and articles produced in humanistic and social disciplines over the recent years one is led to believe that we are living in a time of "turns". New methodological turns are announced time and again, for instance, most recently, the performative turn, the spatial turn, and the iconic turn. Although each of these turns was first announced within a particular discipline, the ambition has usually been greater, proclaiming changes in the humanistic and social sciences in general. Evidently, scholars are eager to find methodological platforms to bridge the current classifications of sciences and to create new interdisciplinary fields of research. Clifford Geertz has aptly termed the process "blurring of genres". As has been argued by Mieke Bal, interdisciplinarity in the humanities mainly relies on concepts. Progress in the humanities means, first and foremost, emergence of new concepts and change or expansion of the semantic space of the old ones. The last few years indeed appear to have been the heyday for travelling concepts.

In order to give a survey of the new "turns", emergent interdisciplines and travelling concepts in the humanities, Estonian academic journal Keel ja Kirjandus ("Language and Literature") recently published a special issue on "Humanities: States and Prospects". The editor of the special issue, Marek Tamm, also interviewed at this occasion several internationally renowned

Address: Winfried Nöth, University of Kassel, FB 02, Georg-Forster-Str. 3, D-34109 Kassel, Germany; e-mail: noeth@uni-kassel.de.

2 Address: Eero Tarasti, Department of Musicology, University of Helsinki, Vironkatu 1, 00014 Helsinki, Finland; e-mail: eero.tarasti@helsinki.fi.

3 Address: Marek Tamm, Estonian Institute of Humanities, Tallinn University, Uus-Sadama 5, 10120, Tallinn, Estonia; e-mail: marek.tamm@tlu.ee. 
scholars about the recent trends and future perspectives in the humanities. The responses from two of them follow below. ${ }^{4}$

M.T.: How do you evaluate the developments in the humanities during the couple of recent decades? In your mind, what have been the most important trends, changes and achievements?

W. N.: The decades towards the turn of the millennium have brought an increasing number of mostly self-proclaimed epochal turns in the humanities. After the "linguistic turn" in philosophy, we have seen the "semiotic turn" in linguistics, the "cognitive turn" in psychology, the "pictorial turn" in media studies, the "iconic turn" in aesthetics, the "cultural turn" in literary studies, and the "performative turn" in cultural studies. More recently, with the advent of posthumanism, the foundations of the humanities themselves seem to have suffered a deadly blow from which recuperation appears more than difficult. Is this zigzag course of successive changes of direction the symptom of a growing disorientation in the humanities, or is it nothing but the mere rhetorical gesture of scholars in defence of their own positions in the territory of humanistic studies?

Despite their apparent divergences, the various recent and current turns in the humanities have two directions in common, the first forward towards new intellectual horizons in a field of study felt to have become too narrow, the second looping back towards the humanities themselves in self-reflexive reconsideration of their own foundations which appeared necessary with each of the new changes of direction. At the turn of the millennium, the expansion of its horizons continues to be a challenge to the humanities. The growth of its domain certainly continues to be impressive, but in the wake of postmodernism, it seems that the most significant direction in the development of humanist studies is the one towards the self-reflexivity which lies in the relation of humanism and its object of study, which includes the humanities themselves.

The self-referential loop which has become a current design feature of the humanities is the sign of a paradigm shift from modernism to postmodernism in the course of which we have abandoned the modernist hubris of the once cherished view that the language of the humanist is a metalanguage speaking above, and aloof from, the objects which it seeks to investigate. In the first decades of the 20th century, for example, semiotics, the study of signs in culture and nature, confidently presented itself as the metalanguage of language, a system of metasigns serving as an instrument in the study of signs, and later, as the metamedium for revealing the deceptive strategies of the media. Today, we know that metasigns are nothing but signs, too, and the

4 The earlier Estonian version has been published in Keel ja Kirjandus 8/9 (2008), pp. 740-743 and 744-746. 
media are not the metalanguage of everyday language and discourse but represent a world which is in itself highly mediated before and while it is mediating in the media.

Representation appears hence to be impossible without self-referential loops in which signs are signs about signs, communication is communication about communication, reports are reports about reports, and mediations are mediations of mediations. In times which have lost their confidence in the grand narratives because everything seems to have been said before, the humanities have turned towards the signs which they once considered to be their instruments of reflection and which they now have discovered to be autonomous mediators of their own mediality. With this new turn, the humanities have gained the insight that the self-referential nature of their reflections does not mean a circulus vitiosus but a circulus virtuosus, in which the humanist is turning towards the humanities.

E.T.: It seems to me that unfortunately the humanities have been to a great extent loosing their former position as the cornerstone of European academic culture. Less and less universities seem to believe and invest in the idea of 'culture', Bildung, sivistys, as such. It is paradoxical that a discipline like semiotics has also accelerated this development. When it was launched as a new science in the 1960s it had a two-fold impact on high and popular culture. High culture was studied with 'modern' and 'efficient' approaches, such as cybernetics, information science, computer studies, formal logic, structural linguistics, and by this means their privileged status was questioned: art and high cultural objects were shown to function according to the same principles as any cultural 'text'. Particularly French structuralist and post-structuralist semiotics were iconoclast by their orientation.

At the same time, popular culture was taken up as a topic of academic discussion by these rigorous methods and thus elevated phenomena to a position of an esteemed object of research that had earlier been considered inappropriate as a topic of the humanities. We can say that high culture lost and popular culture won.

However, new orientations in epistemology, such as phenomenology and hermeneutics, have animated qualitative studies by taking into account how culture appears experienced by a subject. Value aspects, the axiological and ideological nature that are in the core of any humanist approach, have remained topical amidst the age of behaviourism and the natural sciences. It was Kierkegaard who said that the subjective and objective never meet. The same was said as early as by the logical empiricists when they showed, at the beginning of the twentieth century, that phi-phenomena cannot be reduced into ph-phenomena, i.e., to physical entities, and yet people seem to believe in the determinist models of wrongly understood natural sciences. The radical essence of the biosemiotics of the Uexkülls has been that man's symbolic, signifying activities are not reducible to biology — as it has been in 
sociobiology — but that, quite the reverse, all biological and organic processes are processes of semiosis.

M.T.: In which direction, from your point of view, are the humanities heading at present? What are the greatest challenges, the most promising perspectives, as well as the most serious problems a scholar in humanities faces in our time?

W. N.: Nietzsche, Heidegger, Foucault are among the anti-humanists who have proclaimed the end of humanism. Ever since then, the humanities have been pressed towards a position of defense. As the end of humanism continues to be affirmed, the neo-humanists proclaim the return of a renewed humanism. The most recent challenge to the humanist doctrine of the autonomy and freedom of the human mind is the vision of a posthuman world in which humans may no longer be the masters but might become the slaves of those intelligent machines which they once devised as their instruments of rational thought and labor.

While the posthumanists offer evidence of the growth of intelligence in complex systems and the likelihood of a future emergence of complex machines with a growing autonomy from human control and support, the humanists hasten to object that machines will never be able to feel or think since they lack autonomy, rationality, creativity, intentionality, selfreferentiality, and consciousness. At the root of the humanistic objections and the dualistic views of humans and machines is the conviction of a gaping abyss between mind and matter.

What is missing in the ongoing debate is an evolutionary semiotic perspective to overcome the dualistic dilemma between the allegedly semiotic mind and the nonsemiotic material world, a broader view of the cultural semiosphere which extends beyond the sphere of the living. - With the advent of biosemiotics in the last decades of the twentieth century, the study of signs had expanded from the domain of culture to the one of semiosis in nature. At the beginning of the twenty-first century, it has become evident that further expansions are needed.

Intelligent machines are machines involved in sign processes. Are they true sign machines or mere instruments of human agents who use them for purposes of their own? The answer to this question is neither a yes nor a no; it is rather a matter of degree whether machines are involved in sign processes or not. In the study of signs in lifeless but intelligent machines, an important insight can be derived from C. S. Peirce: the sphere of signs is not only a sphere of autonomous living beings producing and interpreting signs. Instead, signs have a semiotic autonomy of their own; by no means are they mere instruments of autonomously acting sign users. The autonomy apparent in the life of signs which restricts the semiotic choices of those who make use of them is perhaps best described by Peirce's insight formulated in 1886: not 
only sign producers but also the signs themselves are the educators of mankind.

Sign machines generate complex signs by means of mechanical devices. If signs evince a semiotic autonomy independently of the way of their production, machines can certainly be said to produce signs. The insight that signs have a life of their own and evince an autonomy in the semiosphere of the products of the human mind outside the human brain is quite compatible with the more recent notion of the "extended mind", according to which the human mind is not merely localized in the confines of the human brain but also extends over its projections into its material environment. Our mind includes its manifestations in its external semiosphere, from personal notes to libraries and data banks. The degree to which the signs mediated by machines evince an autonomy of their own is quite obvious from the way in which computer assistance is transforming our individual ways of writing and methods of research. The medium of the sign machine conveys a message of its own, the sign machine is not merely an instrument of the writer; it turns out to be the co-author of our writing processes.

On the other hand, we have also learned from Peirce as well as from Bakhtin that semiosis is a dialogical process. Our thoughts are addressed to other thoughts of our own, and our reasoning is the dialogical exchange of arguments among the several selves which constitute our mind. Will intelligent machines once be designed to perform inner dialogues of conflicting selves, which are not only symptoms of genuine creativity but also of selfdoubt?

E.T.: The challenge of the humanities is simply how they can survive at all in the globalized world exclusively dominated by values of efficiency and economy. Only those disciplines seem to have chance which can make their results into marketed products for consumption. The university studies in the EU after Bologna aim at short and efficient studies preparing for certain clearcut jobs in labour market, at the least possible costs. The university as a place of growth, deeper understanding of life, a universe of maturing, letting young people reflect on their aims, try and err, search for the values of their future life, a place in which they could follow the principle once expressed by a University rector in the words "Follow your passion - and furnish your mind", seems to be disappearing. Let me say that I am not worried about my own special field, which is music and musicology, since the more there is leisure time in society, the more music is filling it almost like a new religion, as a source of depth and signification of life. Thus music has markets, and musicologists have work. But in general, the idea that universities are all privatized and essentially funded by businessmen seems to be unrealistic at least on the European scale.

The newest fashion in science politics it to establish richly funded socalled 'innovation universities' all over the world designed to do nothing but 
subordinate research for commercial use and for the needs of business life, thus narrowing the chances for serious basic research aiming at true scientific innovations.

Who would have an interest in funding studies about notions such as transcendence, existentiality, modal structures of signs etc.? One factor which may be a force of resistance are national cultures, which some decades ago were still generally considered something of the backward past, but which now seem to be one of the strongest interests to support the humanities. Anything concerning the national heritage or patrimoine, as they say in the Mediterranean culture, has always a 'social order'. Hence, the historical sciences seem to have a future.

On the other hand, in the contemporary world, the idea of national culture seems to have changed to the one of 'picturesque regional qualities' to be enjoyed as tourism. Last autumn, I visited Moldavia in Rumania, and saw how the main means of transportation were still horses and charts. However, I must say: wait for some years, and the same peasants will be hired to 'act' as peasants for tourists and that will be their major source of income; i.e., such humanities whose applications can be made a spectacle, for neo-oral culture, are kept alive.

However, my favourite concept in the more radical semiotics stems from the Southern Italian philosopher Augusto Ponzio, who speaks about diritto di infunzionalità, i.e., the right to dysfunctionality. Such a quietist principle has its roots both in European thought and in American transcendentalism and via those in modern ecological humanism.

One danger in the modern world of communication - which we semioticians have also been creating, sad to say - is that the symbol of humanist culture, the 'book', is loosing its position. Books are being less and less published, and young people read only the Internet and the Wikipedia. Of course, culture does not stem from reading as such but from thinking of what has been read. Yet if the discourse we are maintaining via books of our past and other cultures disappeared one would be close to the end of the humanities. Quite concretely, some years ago the bookstore of Presses Universitaires de France at Place de la Sorbonne in Paris, symbol of humanist research with books about everything, vanished and gave place for a fashion store for American-type youth culture. No one could prevent this from happening.

....aber nicht diese Töne... However, let us also see the positive aspects, the search for meaning and signification for one's life, the joy of becoming more and more competent through education. We are all perpetual students, we who try to be humanists. Modern techno-semiotic society also provides us with unbelievably efficient means for this endeavour as well as for crosscultural understanding. 